\title{
Seismic resistance estimation of multi-story steel frames under ductility level earthquake impact by nonlinear static method
}

\author{
Maksim Zubritskiy ${ }^{1}$, Oleg Ushakov $^{2}$, Linar Sabitov $^{1,3}$, and Karina Nabiullina ${ }^{3}$
}

\author{
${ }^{1}$ Kazan State Power Engineering University, 420066, Krasnoselskaya str., 51, Kazan, \\ Russia \\ ${ }^{2}$ Federal State Autonomous Educational Institution of Higher Education «Ural Federal \\ University named after the first President of Russia B.N.Yeltsin», 620002, 19 Mira street, \\ Ekaterinburg, Russia \\ ${ }^{3}$ Federal State Autonomous Educational Institution of Higher Education «Kazan Federal \\ University», 420008, 18 Kremlyovskaya street, Kazan, Russia
}

\begin{abstract}
The article proposes a technique for taking into account the higher vibration modes under seismic resistance estimation of multi-story steel frames by nonlinear static method. The characteristic point search has also been improved. As part of the study, the proposed method was verified by time history analysis. Proposed technique allows one to significantly reduce the calculation time, while excluding the deficit of seismic resistance.
\end{abstract}

\section{Introduction}

About 300 thousand earthquakes occur in the world every year. The epicenter of most of them is located far from settlements, and the magnitude of the impact is quite small. However, some earthquakes have disastrous effects on entire cities, destroying them and causing colossal economic damage. Thus, increasing the seismic resistance of buildings and structures is one of the most pressing problems of construction in seismically hazardous areas.

According to 1, when performing calculations of building structures taking into account seismic effects, it is necessary to consider two design situations:

- Seismic loads corresponding to the "Strength Level Earthquake" (SLE) level;

- Seismic loads corresponding to the level "Ductility Level Earthquake" (DLE) level.

The purpose of calculations on SLE is determining design solutions to prevent partial or complete operational properties loss. The calculations are performed on the basis of the response spectrum analysis with elastic behavior. 
The purpose of analysis of system under DLE level earthquake is assessing the overall stability, immutability, the structure homogeneity, the admissibility of the accelerations level, displacements, velocities in the building elements, structure, the building structures ability to redistribute external seismic effects due to the formation of plastic hinges and other nonlinear effects. Evaluation of seismic resistance under seismic impact of the DLE level earthquake is carried out on the basis of a time history analysis by integrating the motion equations in the time domain using an accelerations records set. Such calculations require a large time resource, complex software and special qualifications of the engineer.

An alternative to time history analysis is the nonlinear static method - Pushover analysis [2-4]. The structure is subjected to monotonically increasing horizontal forces.

Today it is necessary to perform at least two calculations using different horizontal forces pattern along the system height:

- Inertial forces pattern corresponding to the main vibration form. Seismic resistance estimation with a given distribution can be performed only if the modal mass of considered form or effective modal mass (ratio of structure mass involved in the dynamic response for a given direction of the seismic impact) is not less than $75 \%$;

- Inertial forces pattern, obtained by inertial forces superposition of several vibration modes. In this case, the total modal mass under consideration should not be less than $90 \%$;

- Universal inertial forces pattern distribution in proportion to the masses at the system nodes;

- Adaptive inertial forces pattern, which changes depending on the system nodes movement.

Further characteristic point search on the capacity curve is a laborious process and requires the cumbersome graphs plotting and non-trivial calculations. In modern software, a nonlinear static method is implemented only on the basis of inertial forces pattern corresponding to only one of the vibration modes. In addition, the structure response for single vibration mode under seismic impact is less than results obtained by time history analysis 5. In research 6 maximum horizontal displacements values between two aforementioned methods differ by more than $10 \%$. The difference between the horizontal displacements of the system nodes with decreasing height increases. The maximum difference of results is about $42 \%$.

The article purpose is improving the nonlinear static method in terms of taking into account higher vibration modes, as well as simplifying the characteristic point search. The research object is steel single-span multi-story frames.

\section{Methods for calculating higher mode of vibration}

To determine the system response taking into account the influence of higher vibration modes we consider the following method and introduce the concept of a modified inertial forces system.

Modified inertial forces system means the system of forces obtained based on forces superposition by the method "Square Root of the Sum of Squares" 7, when the displacement of the top of the considered computational model corresponds to the total displacements obtained from linear spectral analysis. The graphic representation of inertial forces summation is shown in Figure 1. 

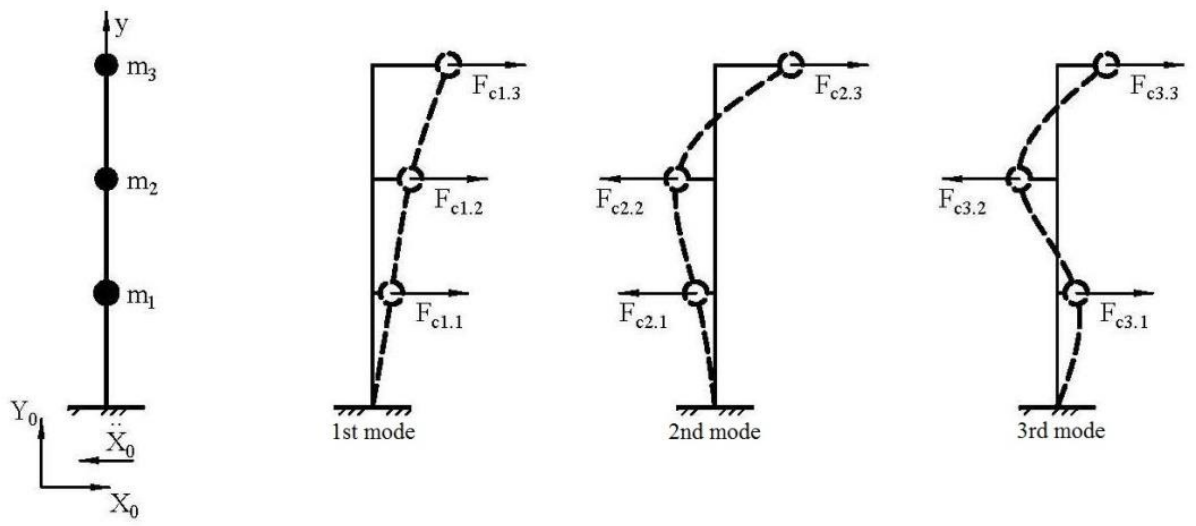

Fig. 1. Graphic representation of modal response summation method "Square Root of the Sum of Squares"

Thus, the modified inertial forces system is determined by (1):

$$
R_{\text {sum }}=\alpha\left(\sum_{i=1}^{n} R_{i}^{2}\right)^{\frac{1}{2}}
$$

where $\quad R_{i}$ - modal structural response corresponding to the $i$-th form of natural vibrations;

$\alpha=\Delta_{R S A} / \Delta_{S R S S}$ - reduction ratio equal to the ratio of maximum displacement of the top node of the system $\Delta_{R S A}$ obtained through response spectrum theory to displacements $\Delta_{S R S S}$, obtained through modified forces system.

According to 8,9 one needs to spend the same amount of energy to destroy a material regardless of the load applied (i.e, static slow, dynamic fast, single or multiple loading). Thus, the linear system deformation energy with an inertial forces modified system (yellow area on Figure 2) is identical to the system deformation energy allowing for plastic deformations (blue area on Figure 2) - equivalent energies concept. The target value of system energy capacity is equal to yellow area under the graph and can be determined based on the modified inertial forces system.

$$
W_{l}=\frac{V_{l} \Delta_{l}}{2}
$$

where $\quad V_{l}-$ shear force at the base of the system obtained through response spectrum analysis;

$\Delta_{l}-$ displacement of the top node of the system. 


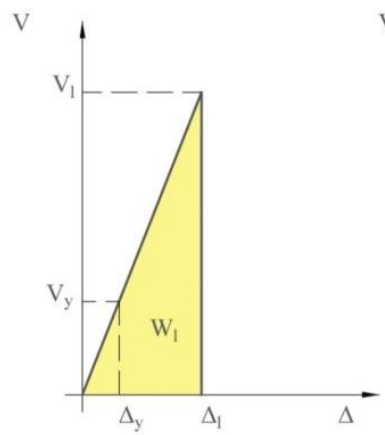

a)

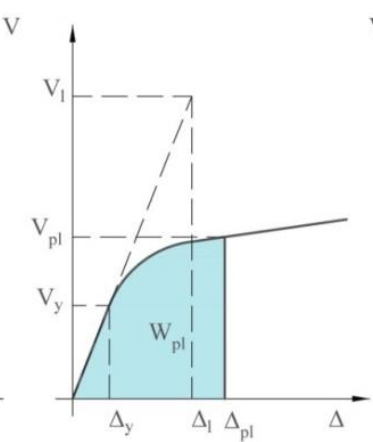

b)

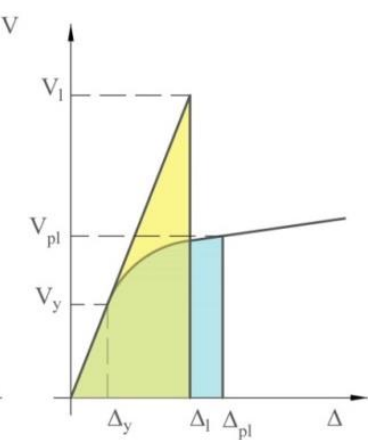

c)

Fig. 2. Energy determination for elastic and elastic-plastic behaviour of a system with one degree of freedom: a) elastic behaviour; b) elastic-plastic behaviour; $c$ ) energy equality for elastic and elasticplastic behaviour

The next stage in seismic resistance assessment is plotting the dependency graph "Shear force $V$ - Displacement of the top node of the system $\Delta$ " - capacity curve - based on a nonlinear static analysis of a system with one degree of freedom under the action of a modified inertial forces system. Each point on capacity curve describes final state of the system for considered seismic impact with monotonically increasing horizontal forces.

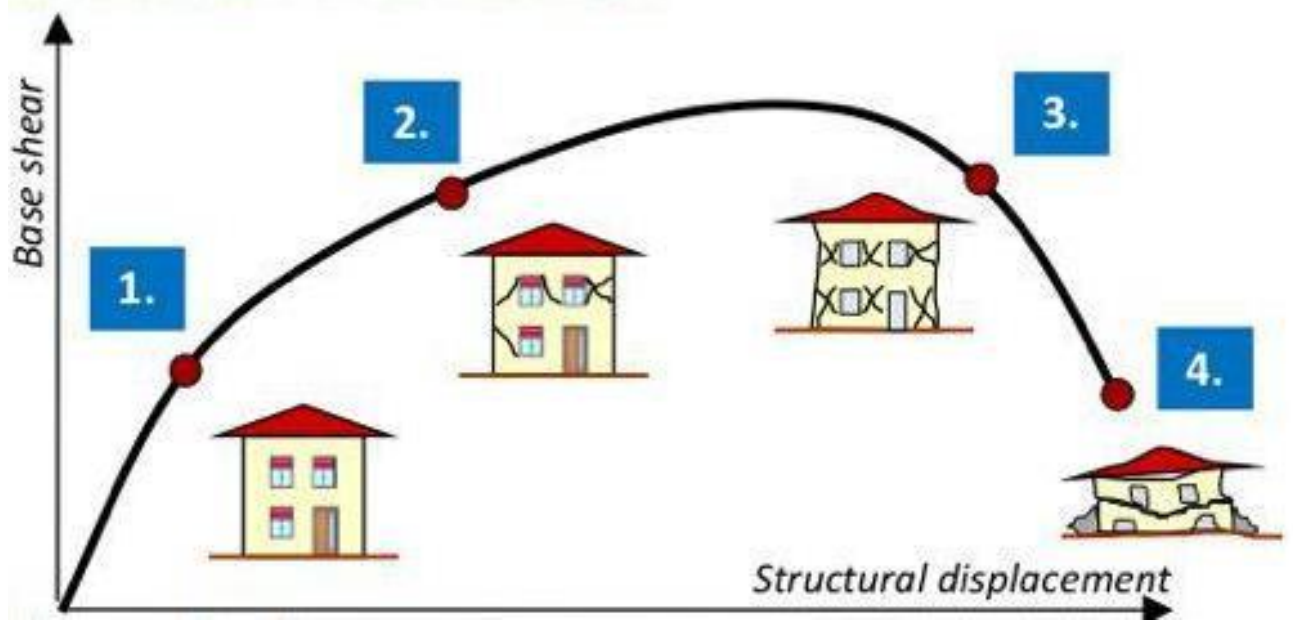

Fig. 3. Capacity curve with points showing criteria for assessing structural reliability

Given that the energies of elastic and elastic-plastic deformation are equal, the obtained value of the top of the system displacement $\Delta_{p l}$ is the target value for assessing the seismic resistance of the entire system. Thus the characteristic point on the capacity curve indicates the maximum displacement of the system top based on the maximum possible energy of a given earthquake According to the maximum displacement of the system top inter-floor displacements, internal forces in the system elements as well as to analyze the inelastic behaviour of joints and system elements can be determined.

Depending on the position of the characteristic point on the bearing capacity curve, one can assess the general nature of the damage to the structure as a whole.

The object of research is steel single-span multi-story frame.

Stress-strain diagram of the steel is shown on Figure 4. To describe the nonlinear behavior of the system elements, isotropic hardening model (Bilinear Kinematic Hardening) 10 was taken as a structural material. Stress-strain diagrams of steel in tension 
and compression are assumed to be the same with corresponding tensile and compressive steel resistance. The yield surface is described by the Von-Mises criterion (Figure 5). The cylinder axis coincides with the axis of hydrostatic compression in the principal stresses coordinate system.

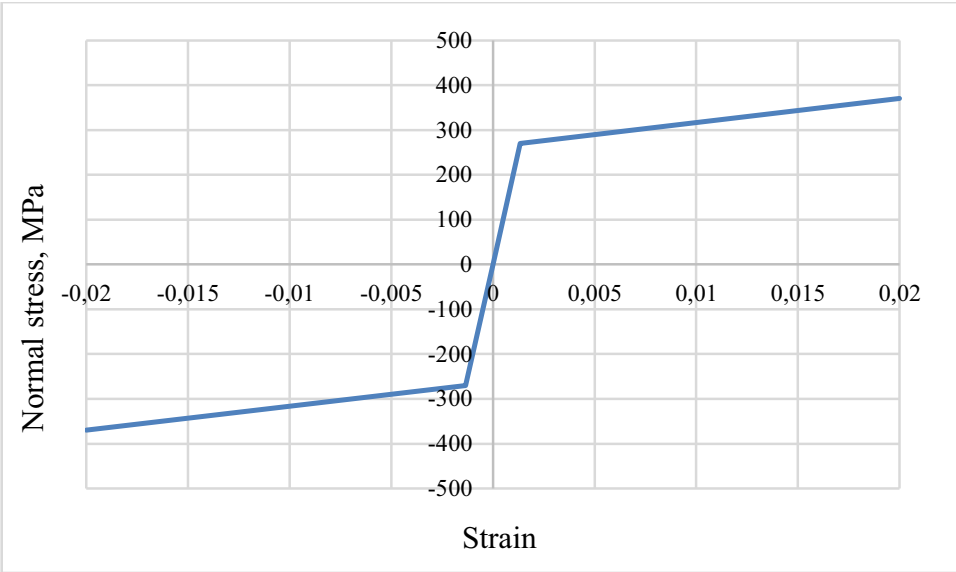

Fig. 4. Stress-strain diagram of steel

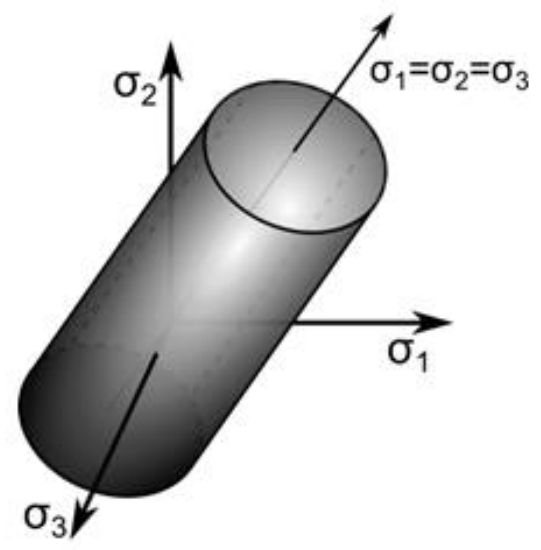

Fig. 5. Von-Mises yield surface in the axes of the main stresses

Seismic actions are given by the following one-component accelerograms acting in the YoZ plane: Iran, 1978 (Erthq. 1); El Centro, USA (California) 1979 (Erthq. 2); Duzce, Turkey, 1999 (Erthq. 3).

Accelerogram records were taken from the database 11.

General view is shown on Figure 6. Geometry and frequency system characteristics are given in Table 1. 
Table 1. Geometry and frequency system characteristics

\begin{tabular}{|c|c|c|c|c|}
\hline \multirow{2}{*}{ № } & \multirow{2}{*}{ Name } & \multicolumn{3}{|c|}{ Value } \\
\hline & & Erthq. 1 & Erthq. 2 & Erthq. 3 \\
\hline 1 & Vertical elements cross-section, $\mathrm{mm}$ & $400(h) \times 3$ & $00(b) \frac{1}{x 12,5(1}$ & $x 10\left(b_{w}\right)$ \\
\hline 2 & Horizontal elements cross-section, $\mathrm{mm}$ & I 400(h) & $x 300(b) \times 12$ & $\left.b_{f}\right) x 8\left(b_{w}\right)$ \\
\hline 3 & Storey height, mm & & 3000 & \\
\hline 4 & Number of storeys & & 6 & \\
\hline 5 & Span, mm & & 6000 & \\
\hline 6 & Young modulus, $\mathrm{Pa}$ & & $2 e^{11}$ & \\
\hline 7 & Yield point, $\mathrm{MPa}$ & & 270 & \\
\hline $\mathrm{g}$ & Tangential modulus, $\mathrm{MPa}$ & & $5,361 e^{3}$ & \\
\hline 9 & Masses $\mathrm{m}_{\mathrm{a}}=\mathrm{m}_{\mathrm{b}}=\mathrm{m}_{\mathrm{c}}, \mathrm{kg}$ & 2000 & 2000 & 2000 \\
\hline 10 & 1 st natural vibration frequency $\mathrm{f}_{1}, \mathrm{~Hz}$ & 1,8836 & 1,8836 & 1,8836 \\
\hline 11 & 2nd natural vibration frequency $\mathrm{f}_{2}, \mathrm{~Hz}$ & 6,0731 & 6,0731 & 6,0731 \\
\hline 12 & 3rd natural vibration frequency $\mathrm{f}_{2}, \mathrm{~Hz}$ & 11,366 & 11,366 & 11,366 \\
\hline 13 & Damping parameter $\alpha_{\mathrm{R}}, \mathrm{s}^{-1}$ & 1,000593 & 1,000593 & 1,000593 \\
\hline 14 & Damping parameter $\beta_{R}, \mathrm{~s}$ & 0,001184 & 0,001184 & 0,001184 \\
\hline
\end{tabular}

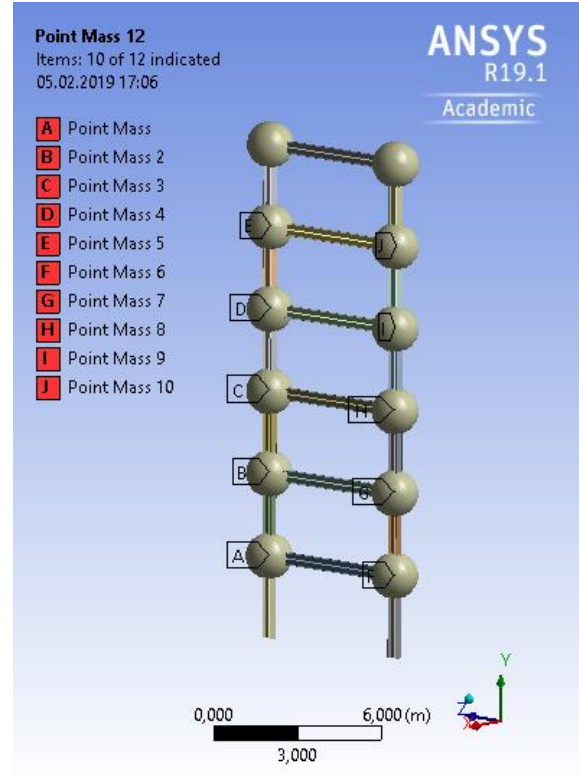

a)

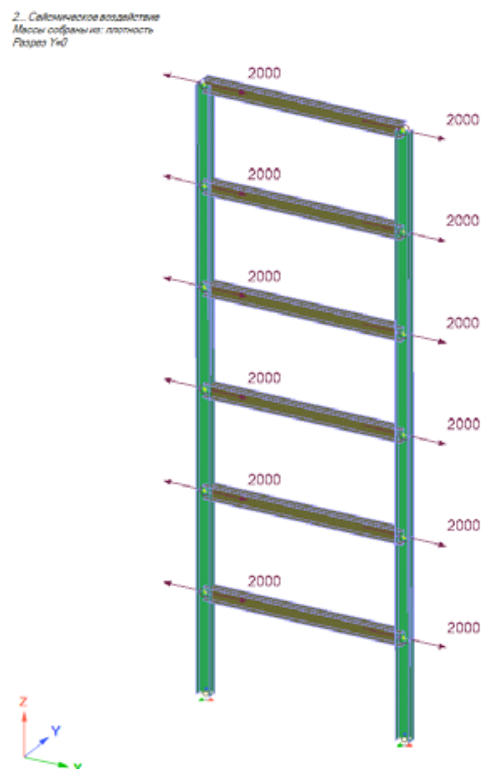

b)

Fig. 6. General view of the design model (a) - ANSYS R18.2 Academic version, (b) - Lira 10.10 
To calculate modified inertial forces system for a given system during the seismic evaluation by the multimodal nonlinear static method, the initial data are the inertial forces of the first three vibration modes.

The inertial forces distribution and the forces resulting system for seismic impact Iran, 1978 (Erthq1) are obtained by response spectrum analysis. Deformed shapes for each vibration form are shown on Figure 7. Table 2 represents the modified inertial forces system for each seismic impact.

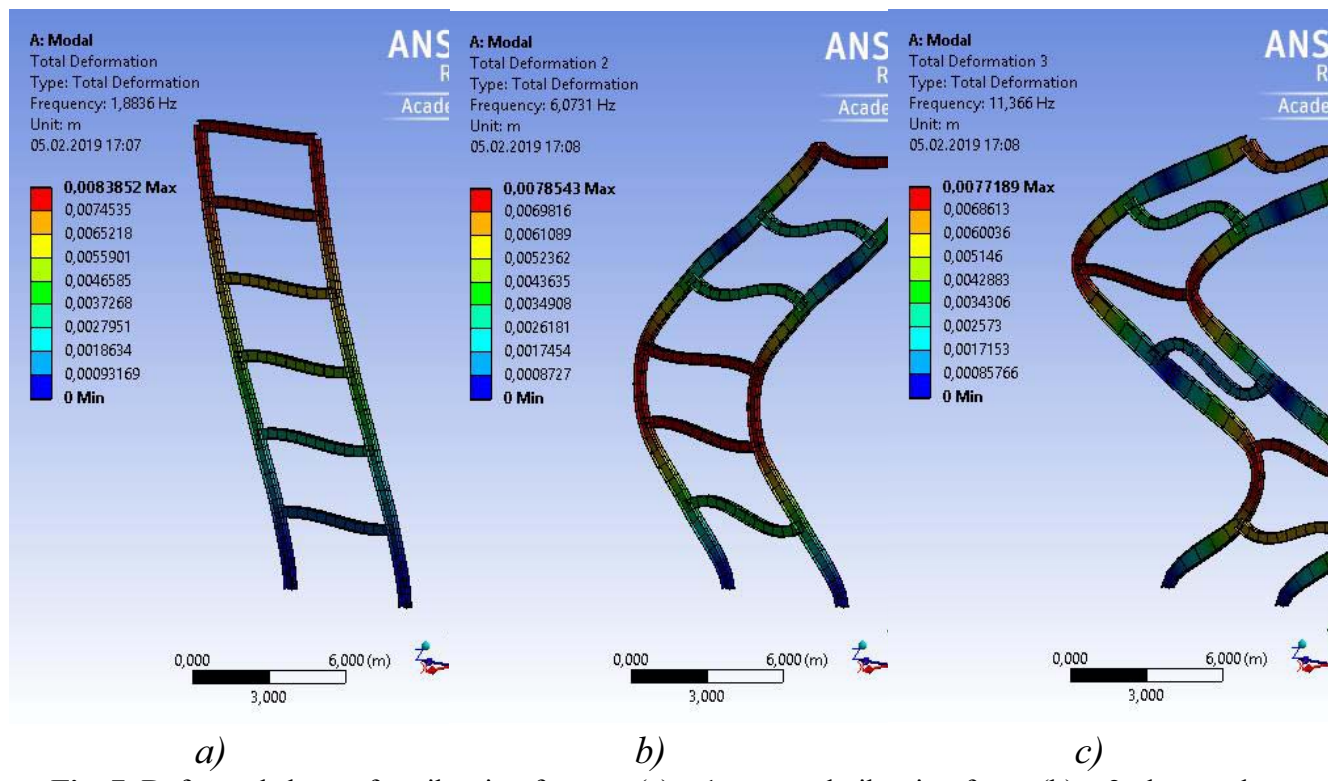

Fig. 7. Deformed shapes for vibration forms: (a) - 1st natural vibration form, (b) - 2nd natural vibration form, (c) - 3rd natural vibration form

Table 2. Modified inertial forces system

\begin{tabular}{lccc}
\hline \multicolumn{1}{c}{ Name } & \multicolumn{3}{c}{ Value } \\
& Erthq. 1 & Erthq. 2 & Erthq.3 \\
\hline $\begin{array}{l}\text { Inertial force at the } 6^{\text {th }} \text { storey after superposition } \\
\text { by the SRSS-method according to (1), } \mathrm{kg}\end{array}$ & 6556.34 & 6612.5 & 7701.1 \\
$\begin{array}{l}\text { Inertial force at the } 5^{\text {th }} \text { storey after superposition } \\
\text { by the SRSS-method according to (1), } \mathrm{kg}\end{array}$ & 5881.07 & 5449.1 & 5825.6 \\
$\begin{array}{l}\text { Inertial force at the } 4^{\text {th }} \text { storey after superposition } \\
\text { by the SRSS-method according to (1), } \mathrm{kg}\end{array}$ & 5126.32 & 5021.0 & 5325.6 \\
$\begin{array}{l}\text { Inertial force at the } 3^{\text {rd }} \text { storey after superposition } \\
\text { by the SRSS-method according to (1), } \mathrm{kg}\end{array}$ & 4414.68 & 4393.5 & 5778.0 \\
$\begin{array}{l}\text { Inertial force at the } 2^{\text {nd }} \text { storey after superposition } \\
\text { by the SRSS-method according to (1), } \mathrm{kg}\end{array}$ & 3479.07 & 3907.5 & 5182.6 \\
$\begin{array}{l}\text { Inertial force at the } 1^{\text {st }} \text { storey after superposition } \\
\text { by the SRSS-method according to (1), } \mathrm{kg}\end{array}$ & 1708.26 & 2172.3 & 2585.8 \\
\begin{tabular}{l} 
Total modal mass, $\%$ \\
\hline
\end{tabular} & 96.29 & 96.24 & 96.24 \\
\hline
\end{tabular}




\section{Results}

To estimate the responses error obtained by the multimodal nonlinear static method, it is necessary tos compare the results with the responses obtained by time history analysis using the acceleration records Erthq1-3.

The calculation results error estimation is presented in Table 3.

Statistical processing was performed to assess the obtained data quality:

- The average value of the error in the horizontal displacements of the system nodes was $8,34 \%$; standard deviation $-7,95 \%$;

- The average value of the error in bending moments in the system elements was $14,6 \%$; standard deviation $-0,89 \%$;

- The average value of the error in shear forces in the elements of the system was $12,29 \%$; standard deviation $-0,52 \%$.

Table 3. The calculation results error estimation

\begin{tabular}{|c|c|c|c|c|}
\hline \multicolumn{2}{|c|}{ Compared parameter } & Time history analysis ${ }^{*}$ & $\begin{array}{l}\text { Nonlinear static } \\
\text { analysis }\end{array}$ & Error, $\%^{*}$ \\
\hline \multirow{6}{*}{ 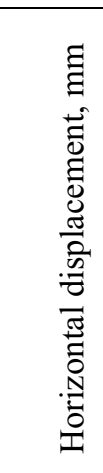 } & $6^{\text {th }}$ storey & $178,3 / 166,98 / 161,78$ & $175,1 / 162,88 / 170,5$ & $\begin{array}{c}-1,79 /- \\
2,46 /+5,11\end{array}$ \\
\hline & $5^{\text {th }}$ storey & $162,2 / 150,84 / 147,02$ & $160,5 / 149,26 / 157,73$ & $\begin{array}{c}-1,05 /-1,05 / \\
+6.79\end{array}$ \\
\hline & $4^{\text {th }}$ storey & $136,9 / 126,18 / 124,00$ & $138,91 / 128,59 / 137,24$ & $\begin{array}{c}+1,47 /+2,41 / \\
+9,65\end{array}$ \\
\hline & $3^{r d}$ storey & $102,7 / 94,125 / 94,15$ & $109,06 / 100,82 / 109,41$ & $\begin{array}{c}+5,83 /+6,641 \\
+13,94\end{array}$ \\
\hline & $2^{\text {nd }}$ storey & $62,2 / 57,25 / 58,81$ & $70,62 / 65,55 / 72,51$ & $\begin{array}{c}+11,92 /+12,6 \\
6 /+18,40\end{array}$ \\
\hline & $1^{s t}$ storey & $23,6 / 21,76 / 22,94$ & $28,90 / 26,81 / 30,42$ & $\begin{array}{c}+18,3 /+18,83 / \\
+24,59\end{array}$ \\
\hline \multirow{2}{*}{\multicolumn{2}{|c|}{$\begin{array}{l}\text { Maximum bending } \\
\text { moment in the } \\
\text { termination, } k N \cdot m \\
\text { Maximum shear } \\
\text { force at the system } \\
\text { base, } \mathrm{kN}\end{array}$}} & $428,31 / 420,93 / 433,18$ & $496,32 / 489,36 / 505,39$ & $\begin{array}{c}+13,70 /+15,8 \\
2 /+14,29\end{array}$ \\
\hline & & $390,62 / 384,38 / 402,08$ & $442,98 / 441,9 / 457,04$ & $\begin{array}{c}+11,82 /+13,0 \\
2 /+12,03\end{array}$ \\
\hline
\end{tabular}

* The table shows the values in the following order: Iran, 1978 (Erthq. 1) / El Centro, USA (California), 1979 (Erthq. 2) / Duzce, Turkey, 1999 (Erthq. 3)

\section{Discussion}

In the mathematical study course, time-domain calculations were performed using records of three accelerations, bearing capacity curves were constructed, non-linear static calculations and modal analyzes were performed for the design model of a single-span multi-story steel frame.

To take into account the higher vibration modes influence under seismic resistance estimation of systems, a method is proposed for searching for the modified inertial forces for the subsequent characteristic point search on the capacity curve - multimodal nonlinear static method. Based on the results of performed calculations complex, it can be concluded 
that proposed method implementation is advisable. The average error value in the results obtained by the time history analysis with the results based on the multimodal nonlinear static method for all structural response criteria does not exceed $15 \%$, while providing a margin for assessing seismic resistance. The authors have proposed an algorithm to automate the proposed technique 13 .

\section{References}

1. Design Code: SP 14.13330.2014. Seismic Building Design Code - Moscow: [w.p.], $2014-125$ c.

2. Applied Technology Council: ATC-40. Seismic evaluation and retrofit of concrete buildings - Redwood, CA, $1996-334$ p.

3. EUROPEAN STANDARD: EUR 25204 EN. Eurocode 8: Seismic Design of BuildingsWorked examples. - Luxembourg: Publications Office of the European Union, $2012-522 \mathrm{p}$.

4. FEMA-356. Prestandard and Commentary for the seismic rehabilitation of buildings American Society of Civil Engineers (ASCE), Reston, VA, 2000 - 519 p.

5. Zubritskiy M.A. Account for the contribution of higher modes under system seismic resistance estimation by nonlinear static method / Ushakov O.Y., Sabitov, L.S. // IOP Conference Series: Materials Science and Engineering, Volume 570, Number 1, 2019 $7 \mathrm{p}$.

6. Zubritskiy M.A. Performance-based seismic evaluation methods for the estimation of inelastic deformation demands resistance estimation by nonlinear static method / Ushakov O.Y., Sabitov, L.S. // IOP Conference Series: Materials Science and Engineering, Volume 570, Number 1, 2019-8 p.

7. Birbraer A.N. Seismic Analysis of Structures. - St. Petersburg: Nauka, $1998-255$ p.

8. Mkrtychev O.V. Safety of buildings and structures during seismic and emergency impacts analysis of buildings: monograph / Moscow State University of Civil Engeneering - Moscow, NRU MGSU, 201 - 152 p.

9. Mkrtychev O.V. Problems of accounting for nonlinearities in the theory of seismic resistance (hypotheses and delusions): monograph / O.V. Mkrtychev, G.A. Ginchvelashvili; Ministry of Education and Science of the Russian Federation, Moscow State University of Civil Engeneering - Moscow, NRU MGSU, 2012 - 192 p.

10. ANSYS HELP // URL: https://ansyshelp.ansys.com/

11. PEER Ground Motion Database // URL:https://ngawest2.berkeley.edu/

12. Zubritskiy M.A. Performance-based seismic evaluation methods for the estimation of inelastic deformation demands / Ushakov O.Y., Sabitov L.S // IOP Conference Series: Materials Science and Engineering, Volume 570, Number 1, 2019 - 7 c.

13. Certificate of state registration of the program for electronic computer №2019667065.Multimodal nonlinear static method for system seismic evaluation MPA1. Copyrightholder: Zubritskiy Maksim Aleksandrovich. The authors: Sabitov L.S., Zubritskiy M.A., Ushakov O.Y. Request 2019663503; state date registration in the electronic computer program registry $18.12 .19-1 \mathrm{p}$. 